\title{
EFEKTIVITAS PENGGUNAAN ENGLISH CLASSROOM EXPRESSION UNTUK GURU SMP-SMA
}

\author{
Elyza Martiarini \\ Pendidikan Bahasa Inggris, Fakultas Bahasa dan Seni, \\ Universitas Indraprasta PGRI \\ elyza.martia@gmail.com
}

\begin{abstract}
Abstrak
Proses pembelajaran pada satuan pendidikan diselenggarakan secara interaktif, inspiratif, menyenangkan, menantang, memotivasi peserta didik untuk berpartisipasi secara aktif serta memberikan ruang yang cukup bagi prakarsa, kreativitas, dan kemandirian sesuai dengan bakat, minat, dan perkembangan fisik serta psikologis peserta didik. Dalam pelaksanaannya, guru dianjurkan untuk menggunakan bahasa Inggris seoptimal mungkin sekalipun dengan siswa yang masih pasif dalam berbicara. Beberapa guru harus melaksanakannya, walaupun mereka sendiri menyadari betul bahwa karena bukan bidangnya, maka banyak hal yang tidak bisa tersampaikan dengan baik. Dalam pengajaran, guru menentukan berbagai macam ekspresi yang akandiucapkan dalam bahasa Inggris. Kemudian, pada tahapan dalam suatu pelajaran, guru mengajarkan siswa untuk menggunakan ekspresi dalam bahasa Inggris (English Classroom Expression). Alasan utamanya adalah agar guru dapat menerapkan ekspresi-ekspresi tersebut pada situasi nyata yang sedang terjadi pada saat itu sehingga akan nampak alami apa adanya. Selain itu siswa akan lebih mudah mempelajari hal-hal yang sifatnya nyata. Maksudnya adalah dengan mengajarkan instruksi-instruksi pada hal-hal dimana siswa menggunakan untuk pertama kali, mereka perlu dihadapkan pada suatu situasi yang nyata dan terjadi pada ekspresi-ekspresi atau instruksiinstruksi yang lainnya.
\end{abstract}

Kata kunci: Efektifitas, English Classroom Expression, Guru

\begin{abstract}
The learning process in the educational unit is organized interactively, inspirative, fun, challenging, motivate learners to actively participate and provide adequate space for initiative, creativity, and independence according to the talent, interest, physical and psychological development of learners. Practically, teachers are encouraged to use English as optimally as possible even with students who are still passive in speaking. Some teachers have to do it, although they themselves are well aware that because it is not the field, there are many things that cannot be conveyed well. In teaching, teachers determine a variety of expressions that can be pronounced in English. Then, at a stage in a lesson, the teacher teaches students to use English Classroom Expression. The main reason is that teachers can apply these expressions to real situations that are happening at that moment so that it will look natural as it is. In addition students will more easily learn things that are real. The point is that by teaching instructions on the things that students use for the first time, they need to be exposed to a real situation and occur on other expressions or instructions.
\end{abstract}

Keywords: Effectiveness, English Classroom Expression, Teacher 


\section{PENDAHULUAN}

Dalam ranah komunikasi global, Bahasa Inggris memegang peranan penting dan digunakan secara luas sebagai bahasa pergaulan, perdagangan dan pendidikan.Karena pentingnya bahasa Inggris tersebut, kini diajarkan di sekolah mulai dari tingkat SLTP sampai dengan perguruan tinggi. Bahkan di beberapa kota besar, bahasa Inggris sudah dikenalkan ditingkat SD sebagai pengenalan bahasa asing yang memang sangat membantunya kelak. Tuntutan kemajuan ilmu pengetahuan dan teknologi inilah yang mengharuskan kita untuk selalu belajar.

Bahasa Inggris di Indonesia berstatus sebagai bahasa asing dan tentu hanya dipelajari di lembaga pendidikan formal dan non-formal tertentu dan juga hanya digunakan di tempat-tempat tertentu (Marhum, 2008; Marhum2009). Namun, dalam kaitan dengan penerapan kebijakan bahasa di lembaga pendidikan formal, penggunaan bahasa Inggris sebagai bahasa pengantar dan juga penggunaan dwi-bahasa (Bahasa Indonesia-Inggris) merupakan rekomendasi dari kebijakan bahasa dan pendidikan. Diharapkan dengan pennggunaan bahasa Inggris sebagai bahasa pengantar dan penggunaan dwibahasa dapat meningkatkan keterampilan bahasa Inggris (language skills) siswa-siswa dan gurugurunya (Coady \& O'Laorie, 2002; Corson, 1990).

Crystal (1997) seorang Professor Lingusitik dari Inggris mengatakan bahwa suatu bahasa dapat dikategorikan sebagai bahasa global atau bahasa internasional bila bahasa tersebut diakui dibanyak negara di seluruh dunia dan secara alami memilki status global dan memainkan peranan penting secara global. Crystal (1997, p.2) secara lugas menyebutkan bahwa:
English is a global language because it is spoken as a first language, a second language or third language by people around the world. He further explains that in order to gain a global status, two things should be considered. First, the language must be recognized as an official language and it is widely used. Second, although the language does not have any official status, it is widely and popularly taught as a foreign subject.

Crystal mengemukakan bahwa Bahasa Inggris adalah bahasa global karena digunakan sebagai bahasa pertama, bahasa kedua dan sebagai bahasa ketiga atau bahasa asing oleh banyak orang di seluruh dunia.Selanjutnya dijelaskan oleh Crystal bahwa untuk memperoleh status global (internasional), dua hal harus dipertimbangkan.Pertama, bahasa tersebut harus diakui sebagai bahasa resmi dan digunakan secara luas.Kedua, meskipun bahasa tersebut tidak memiliki status resmi, bahasa tersebut sangat popular dan diajarkan dan atau digunanakan secara luas di berbagai negara di seluruh dunia.

Bahasa Inggris memenuhi syarat sebagai bahasa global atau bahasa internasional karena memenuhi criteria seperti yang disebutkan diatas tersebut karena dewasa ini bahasa Inggris sangat popular digunakan di banyak negara dan diajarkan di sekolah-sekolah di seluruh dunia, termasuk di negara-negara yang tidak menggunakan bahasa Inggris secara resmi (Pennycook, 1994; Crystal, 1997).

Kenapa bahasa Inggris menjadi bahasa internasional? Menurut sejarah bahasa Inggris, ada hubungan yang dekat antara bahasa yang dominan dan 
kekuasaan (power).Tidak ada bahasa yang dapat diakui sebagai alat komunikasi internasional tanpa dasar kekuasaan yang kuat secara militer, politik dan ekonomi (Ingram, 1993;Pennycook 1994; Crystal 1997).

Namun, untuk menjadi bahasa global tidak ada kaitannya dengan banyaknya jumlah penutur bahasa tersebut tetapi hal ini sangat berkaitan erat dengan status penutur bahasa tersebut (Cook, 1994; Crystal 1997). Contohnya, bahasa Latin pernah menjadi bahasa Internasional dan hal ini tidak ada kaitannya dengan jumlah penutur bahasa Latin namun sebaliknya sangat berkaitan dengan pengaruh yang kuat dari keakasaran Romawi pada masa itu. Selanjutnya, walapun bahawa china memilki penutur terbanyak di dunia, bahasa China sampai sekarang masih belum dikategorikan sebagai bahasa Internasional seperti bahasa Inggris.

Menurut Crystal (1997), eksistensi bahasa global melahirkan kekuasaan linguistic. Dewasa ini bangsa yang menggunakan bahasa Inggris sebagai bahasa pertama atau bahasa kedua atau bangsa yang mampu menggunakan bahasa Inggris dengan baik diasumsikan memilki kekuasaan dan dapat memperoleh akses untuk mengembangkan karir mereka di arena internasional (Ingram, 1993; Bruthiaux, 2002). Sebaliknya, mereka yang tidak menguasai bahasa Inggris akan mengalami kesulitan.

Bahasa Inggris berkedudukan sebagai bahasa asing pertama (first foreign language) yang diajarkan dalam pembelajaran formal di Indonesia yang dimulai pada tingkat sekolah menengah pertama (SMP).Dalam pempelajari bahasa Inggris, umumnya siswaakan lebih memahami kosakata yang diberikan jika kata tersebut diucapkan dalam bentuk instruksi sederhana yang digunakan berulang-ulang. Oleh karena itu, dalam kurikulum Bahasa Inggris, ekspresi-ekspresi instruksi sederhana dalam konteks kelas (classroom instructions/ expressions) seperti "close the door" "open the window", "raise your hands" dan "clean the blackboard" dipergunakan dengan cara yang sederhana dan dengan intensitas yang tinggi.

Tingkat pencapaian kompetensi yang tinggi dalam bahasa Inggris ditandai dengan keterampilan berbahasa Inggris yang lancar dan akurat, baik dari segi tatabahasa maupun ucapan (Saibah, 2009). Agar pencapaian kompotensi dalam bidang studi dan bahasa Inggris tinggi dan seimbang, perlu upaya pengembangan program-program pendukung secara nyata antara lain: Penciptaan suasana akademik dan sosial yang mendukung, penyelenggaraan bridging course bahasa Inggris, penyelenggaraan self-access learning center dan pelaksanaan kegiatan "English Experience day" di sekolah secaraefektif.

Diknas

(2007,

merekomendasikan perlu dikembangkan model pembelajaran dalam bahasa Inggris yang sesuai dengan ciri dan karakter yang ada pada sekolah pelaksana program. Berikut ini diuraikan beberapa model pembelajaran yang dimaksud:

1. Terpisah (Parallel). Perkembangan bahasa siswa difasilitasi melalui kegiatan penunjang di luar pembelajaran utama (misalnya MIPA) dalam bahasa Inggris yang diikuti siswa di sekolah: (a) siswa menerima pelajaran tambahan berupa English for Mathematics and Science yang dilakukan oleh guru bahasa Inggris dan atau guru MIPA. (b) tim teaching antara guru Bahasa Inggris dan guru MIPA. (c) Pembelajaran MIPA melalui bahasa Inggris dilaksanakan secara 
bertahap. (d) Peningkatan kemahiran bahasa Inggris.

2. Terpadu

(Integrated).

Pengembangan bahasa siswa difasilitasi secara terpadu dalam pembelajaran menggunakan bahasa Inggris. Artinya siswa menerima materi English for Mathematics and science bersamaan ketika mereka menerima pelajaran Matematika dan Ilmu pengetahuan Alam dalam bahasa Inggris.

Pembelajaran Bahasa Inggris secara terpadu diyakini dapat membantu siswa untuk lebih mudah menguasai Bahasa Inggris. Salah satu penerapan Bahasa Inggris terpadu adalah dengan menggunakan Bahasa Inggris sebagai bahasa pengantar dalam mata pelajaran lain. Interaksi dalam proses pembelajaran sangatlah penting karena kelakakanmembantu peserta didik dalam memahami dan mengembangkan pembelajaran mereka. Selain itu tentunya juga akan menumbuhkan keterampilan sosial mereka. Memaksimalkan interaksi di dalam kelas dengan menggunakan instruksi dan ekspresi bahasa Inggris dalam pembelajaran adalah merupakan bagian penting dari peran guru sebagai fasilitator.Memang tidak mudah jika belum terbiasa. Interaksi antar peserta didik atau anggota kelas lainnya tidak akan terjadi secara begitu saja, akan tetapi seorang guru harus mempertimbangkan rencana pembelajarannya secara matang sebelum mengajar dan secara khusus memasukkan aspek interaksi ekspresi berbahasa Inggris ini di dalam perencanaan mengajar itu.

Guru merupakan tokoh sentral dalam proses pembelajaran di dalam kelas. Guru dituntut agar dapat menjadi motivator yang mendorong siswa untuk lebih mandiri dan senang belajar.Oleh karena itu, guru harus memiliki kompetensi yang memadai dalam memilih, mengadaptasi dan menciptakan metode pembelajaran yang sesuai dalam menerapkan interkasi menggunakan ekspresi Bahasa Inggris kepada para siswa.Selain itu juga guru harus dapat menggunakan berbagai macam media pembelajaran yang sesuai dan menyenangkan.

Yayasan Perguruan Jagakarsa atau yang lebih dikenal dengan Yaperjasa merupakan salah satu lembaga pendidikan yang terdiri dari SMK dan SMPyang banyak memberikan kontribusi dalam pendidikan untuk peserta didik khususnya daerah masyarakat Jagakarsa dan sekitarnya. Lembaga Pendidikan Yaperjasa memiliki komitmen akanterus melakukan perubahan paradigma sesuai perkembangan informasi dan teknologi dengan mengoptimalkan pendidikan yang komprehensif dan berorientasi pada peningkatan pendidikanintelektual spritual danemosional.

Kegiatan belajar mengajar di Yaperjasa menggunakan kurikulum KTSP dan Kurikulum 2013 dengan pendekatan sesuai kebutuhan peserta didik yang mengacu pada ketentuan kurikulum Pendidikan Nasional. Bahasa Inggris memang pelajaran wajib di sekolah ini.Perhatian sekolah terhadap Bahasa Inggris sangat tinggi.Hal ini terlihat dari tersedianya English Club sebagai ekstrakurikuler di Yaperjasa.

Sebagai salah satu lembaga penyelenggara pendidikan, Yaperjasa terus berusaha mengembangkan pelayanannya. Salah satu cara peningkatan pelayanan yang dilakukan oleh pihak Yaperjasa adalah dengan memberikan pelatihan kepada guru-guru tentang metode yang mutakhir dan sesuai dengan konsep pendidikan Menengah dan Kejuruan. Oleh karena itu, tim tergerak untuk melaksanakan kegiatan pengabdian masyarakat dengan melaksanakan pelatihan English Classroom Expression khususnya guru-guru SMP 
dan SMK di Yayasan Perguruan Jagakarsa, Jakarta Selatan.

\section{METODE PELAKSANAAN}

Sasaran kegiatan pengabdian masyarkat ini adalah para guru SMP dan SMK Yayasan Perguruan Jagakarsa, Jakarta Selatan. Materi yang digunakan dalam kegiatan ini aadalah berupa English Classroom Expression, dengan prosedur sebagai berikut:

1. Melakukan presentasi dan memberikan penjelasan mengenai prosedur atau langkah-langkah pembelajaran secara rinci serta kelebihan-kelebihan tentang English Classroom Expression.

2. Melakukan presentasi dan memberikan penjelasan mengenai klasifikasi capaian aspek yang ditekankan.

3. Membimbing dan mendampingi para guru SMP dan SMK Yayasan Perguruan Jagakarsa dalam melakukan praktek atau simulasi sederhana dalampelatihan tersebut.

4. Memberikan output berupa notebook yang akan dijadikan pegangan bagi para guru untuk melakukan kegiatan pembelajaran.

Berikut ini adalah rangkaian keseluruhan kegiatan pelatihan Yayasan Perguruan Yaperjasa tentang English Classroom Expression yang bertugas sebagai fasilitator, motivator, koordinator, serta mediator pembelajaran Bahasa Inggris.

1. Awal Kegiatan Pengabdian Kepada Masyarakat

Tim melakukan diskusi secara bersama mengenai tema yang berkaitan dengan kegiatan pengabdian masyarakat. Setelah sepakat, tim menentukan bahwa judul untuk pengabdian masyarakat adalah "Pelatihan Pelatihan English Classroom Expression Di Yayasan
Perguruan Jagakarsa, Jakarta Selatan".

2. Pelaksanaan Kegiatan Pengabdian Kepada Masyarakat berlangsung selama 5 minggu. Kegiatan yang dilakukan antara lain :

a. Di minggu pertama, Ketua tim abdimas melakukan observasi dan menentukan waktu pelatihan selanjutnya.

b. Minggu kedua, tim melakukan presentasi dan memberikan penjelasan mengenai prosedur atau langkah- langkah pembelajaran secara rinci serta kelebihan-kelebihan tentang English Classroom Expression.

c. Minggu Ketiga, tim melakukan preview dan review presentasi dan memberikan penjelasan mengenai klasifikasi capaian aspek yang ditekankan.

d. Minggu keempat, tim mendampingi para guru SMP dan SMK Yayasan Perguruan Jagakarsa dalam melakukan praktek atau simulasi sederhana dalam pelatihan secara langsung di kelas.

e. Minggu kelima, tim melakukan evaluasi mengenai pelatihan Classroom English Expression kepada siswa Yaperjasa.

Tujuan yang ingin dicapai pada kegiatan ini adalah meningkatkan kompetensi guru Yayasan Perguruan Jagakarsa dalam menerapkan interaksi berbahasa Inggris secara menyenangkan kepada siswa melalui English Classroom Expression.Adapun sasaran dalam kegiatan ini adalah para guru SMP dan SMK Yayasan Perguruan Jagakarsa, Jakarta Selatan.

Luaran yang akan dihasilkan adalah berupa note book yang berisi tentang kumpulan English Classroom Expression berbahasa Inggris beserta artinya yang nantinya dapat digunakan 
oleh para guru di kelas untuk menerapkan instruksi dan ekspresiekspresi berbahasa Inggris kepada siswa di SMP dan SMK Yayasan Perguruan Jagakarsa.

\section{HASIL DAN PEMBAHASAN}

Dari pelaksanaan kegiatan pengabdian kepada masyarakat yang telah dilaksanakan di Perguruan Yaperjasa, yang diperoleh antara lain:

Tabel 1

Perbedaan Pembelajaran Sebelum dan Sesudah Menggunakan Classroom Expression

\begin{tabular}{|c|c|c|}
\hline $\begin{array}{l}\text { Indikator } \\
\text { Perubahan }\end{array}$ & $\begin{array}{c}\text { Pembelajara } \\
\text { n Sebelum } \\
\text { Menggunak } \\
\text { an } \\
\text { Classroom } \\
\text { Expression }\end{array}$ & $\begin{array}{c}\text { Pembelajaran } \\
\text { Setelah } \\
\text { Menggunaka } \\
\text { n Classroom } \\
\text { Expression }\end{array}$ \\
\hline $\begin{array}{l}\text { Peran } \\
\text { Guru }\end{array}$ & $\begin{array}{l}\text { - Pembela } \\
\text { jaran } \\
\text { cenderu } \\
\text { ng biasa } \\
\text { saja, } \\
\text { guru } \\
\text { hanya } \\
\text { mengaja } \\
\text { r biasa } \\
\text { tanpa } \\
\text { ada } \\
\text { tampilan } \\
\text { yang } \\
\text { menarik } \\
\text { di kelas. } \\
\\
\text { Guru } \\
\text { tampil } \\
\text { biasa } \\
\text { saja }\end{array}$ & 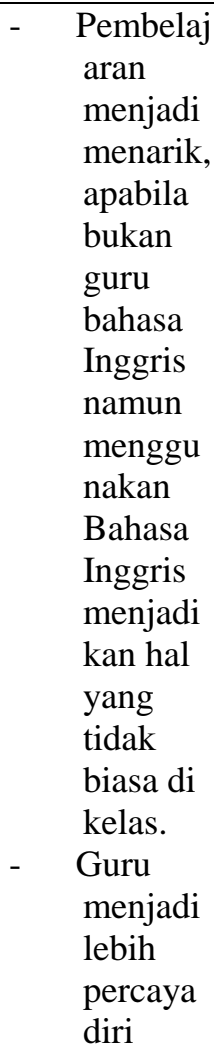 \\
\hline $\begin{array}{l}\text { Pengemba } \\
\text { ngan } \\
\text { Materi } \\
\text { Ajar }\end{array}$ & $\begin{array}{l}\text { - Materi } \\
\text { ajar } \\
\text { merupak } \\
\text { an }\end{array}$ & $\begin{array}{l}\text { - } \quad \text { Materi } \\
\text { ajar } \\
\text { merupak } \\
\text { an }\end{array}$ \\
\hline
\end{tabular}

\begin{tabular}{|c|c|}
\hline $\begin{array}{l}\text { materi } \\
\text { asli } \\
\text { sesuai } \\
\text { dengan } \\
\text { mata } \\
\text { pelajara } \\
\text { n di } \\
\text { sekolah } \\
\text { dengan } \\
\text { menggu } \\
\text { nakan } \\
\text { penganta } \\
\text { r Bahasa } \\
\text { Indonesi } \\
\text { a }\end{array}$ & $\begin{array}{l}\text { materi } \\
\text { yang } \\
\text { berupa } \\
\text { mata } \\
\text { pelajara } \\
\text { n yang } \\
\text { asli } \\
\text { yang } \\
\text { dimodifi } \\
\text { kasi } \\
\text { menggu } \\
\text { nakan } \\
\text { ekspresi } \\
\text { berupa } \\
\text { instruksi } \\
\text {, salam, } \\
\text { maupun } \\
\text { sapaan } \\
\text { menggu } \\
\text { nakan } \\
\text { Bahasa } \\
\text { Inggris } \\
\text { sehingg } \\
\text { a siswa } \\
\text { menjadi } \\
\text { tertantan } \\
\text { g. } \\
\text { Tidak } \\
\text { menutup } \\
\text { kemung } \\
\text { kinan } \\
\text { penggun } \\
\text { aan } \\
\text { Bahasa } \\
\text { Inggris } \\
\text { sebagai } \\
\text { pengant } \\
\text { ar pada } \\
\text { mata } \\
\text { pelajara } \\
\text { n selain } \\
\text { Bahasa } \\
\text { Inggris }\end{array}$ \\
\hline
\end{tabular}




\begin{tabular}{|l|l|c|}
\hline Peran & - Siswa & - Siswa \\
Siswa & cenderung & cenderu \\
& bosan dan & ng aktif \\
& monoton & karena \\
dengan & interaksi \\
interaksi & yang \\
& yang sama & ditimbul \\
dari awal & kan \\
& sampai & menjadi \\
& akhir & lebih \\
& pembelajara & menarik \\
& n. & dan \\
& & spontan. \\
& & Siswa \\
& & menjadi \\
& & lebih \\
& & percaya \\
& & diri \\
& & menggu \\
& & nakan \\
& & Bahasa \\
& & Inggris \\
\hline Kosakata & Tidak & Kosakata \\
Bahasa & menggunaka & Bahasa \\
Inggris & n Bahasa & Inggris \\
yang & Inggris & menjadi \\
diperoleh & bebagai & bertambah \\
& pengantar & menjadi \\
& terbiasa \\
\hline
\end{tabular}

Berdasarkan table di atas, hasil penerapan penggunakan Classroom Expression antara lain:

Peran guru menjadi sosok yang menarik di kelas. Hal ini dikarenakan belum terbiasanya para siswa menggunakan Bahasa Inggris selain di mata pelajaran Bahasa Inggris. Guru menjadi pribadi yang menyenangkan dan terlihat akrab dengan para siswa sehingga diharapkan materi ajar yang disampaikan dapat diterima dengan baik oleh para siswa.

Penerapan materi ajar menggunakan classroom expression terlihat lebih menyenangkan dan lebih hidup. Siswa terlihat mejadi tertantang untuk terlibat dalam pembelajaran.

Selanjutnya, peran siswa pada pembelajaran menggunakan classroom expresion menjadi lebih memperkaya kosakatanya dalam Bahasa Inggris.
Nantinya, siswatidak akan merasa canggung mengucapkan bahasa Inggris karena terbiasa menggunakan bahasa Inggris.

Secara keseluruhan, penggunaan classrooom expression memberikan suasana baru yang menyenangkan dalam pembelajaran di yayasan Yaperjasa. Guru dan para siswa sama sama memperoleh kesempatan untuk mengembangkan diri dengan menggunakan Bahasa Inggris.

\section{SIMPULAN}

Sesuai dengan hasil yang diperoleh oleh tim, maka dapat disimpulkan bahwa:

1. Penerapan classroom expression memberikan pengaruh yang positif pada pembelajaran di yayasan Yaperjasa Jakarta.

2. Secara keseluruhan, pelatihan ini tidak hanya memberikan kemajuan kepada siswa tetapi juga kepada para guru di yayasan Yaperjasa.

\section{DAFTAR PUSTAKA}

Bruthiaux, P. (2002). Predicting challenges to English as a global language in the $21^{\text {st }}$ century. In Dasgupta \& Tonkin (eds), Language Problems \& Language Planning Journal. Vol 26, p. 129-157.

Coady, M. \& O’Laorie, M., (2002) Mismatches in language policy and practice in education: the case of Gaelscoileanna in the Republic of Ireland. In Sheldon, M. (ed), Electronic Journal of Language Policy. Kluwer Academic Publisher. Netherlands, p. 143-156. 
Corson, D. (1990). Language Policy across the Curriculum. Multilingual Matters LTD. Philadelphia, p.1-19.

Crystal D. (1997). English as a Global Language. Cambridge University Press.

Diknas. (2007). Panduan Penyelenggaraan Rintisan Sekolah Berataraf Internasional (RSBI) untuk Sekolah Menengah Pertama. Direktorat Pembinaan Sekolah Menengah Pertama Kemendiknas Jakarta.

Ingram, D.E,. (1993). Language Policy in Australia 1990s. Paper to the Pre-conference International Workshop on Foreign Language Planning, National Foreign.

Marhum, M. (2008). the Linguistic Awakening in Eastern Indonesia in the Era of Globalisation. In Matthews and Gibbons (Eds). The Process of Research in Education.
Shannon Research Press, Australia. (2009a). Issues in Language, Culture and Education in Eastern Indonesia. Lambert Academic Publishing, Germany.

(2009b). English in Indonesian Schools in the Era of Globalization: the Use of English as Instructional Language at Rintisan Sekolah Bertaraf Internationla in Central Sulawesi. STBA-LIA, Yogyakarta.

Pennycook, A. (1994),The Cultural Politics of English as an International Language. Pearson Education Ltd, England.

Saibah. (1999). Implementing Classroom management for the Teaching of English to the Grade Eight Students of Designated International Rating School (RSBI). Unpublished Masters Thesis, Program Pascsarjana. 